\title{
Truncus arteriosus
}

INSERM

\section{Source}

INSERM. (1999). Orphanet: an online rare disease and orphan drug data base. Truncus arteriosus. ORPHA:3384

Truncus arteriosus (TA) is a rare congenital cardiovascular anomaly characterized by a single arterial trunk arising from the heart by means of a single semilunar valve (i.e. truncal valve). Pulmonary arteries orig inate from the common arterial trunk distal to the coronary arteries and proximal to the first brachiocephalic branch of the aortic arch. TA typically overrides a large outlet ventricular septal defect (VSD). The intracardiac anatomy usually displays situs solitus and atrioventricular (AV) concordance. 